\title{
ENSINO DE FÍSICA: DO EXERCÍCIO À PROVA
}

\author{
FLORIANÓPOLIS/SC JULHO/2018
}

\author{
Gilberto Luiz de Souza Paula - UFSC - gilbertosouzapaula@gmail.com \\ Reginaldo Manoel Teixeira - CA/UFSC - regisfsc@gmail.comgmail.com \\ Ana Ester da Costa - UAB/UFSC - anadepaula2000@gmail.com
}

\author{
Tipo: Relato de Experiência Inovadora (EI) \\ Categoria: Métodos e Tecnologias
}

Setor Educacional: EDUCAÇÃO CONTINUADA EM GERAL

\begin{abstract}
RESUMO
Este trabalho foi realizado com estudantes do $1^{\circ}$ ano do nível médio de uma escola pública Federal na cidade de Florianópolis - SC com a intenção de avaliar a efetividade da proposta de estágio apresentada ao programa de graduação em Licenciatura em Física da UFSC. O uso das redes de computadores e de telefonia móvel como facilitadores de aprendizagem depende da adaptação de ferramental midiático como instrumento pedagógico. Propõe-se uma dinâmica centrada em um ambiente mobile contendo o plano de aula, com o conteúdo teórico, os exemplos, exercícios de fixação resolvidos, um e-mail e um chat para o contato direto com o estagiário/docente para a solução de dúvidas a respeito do conteúdo ministrado em sala, um "Blended-Learning". O resultado atingido foi positivo porque proporciona o acesso direto às deficiências particulares de cada estudante na medida em que uma dúvida mínima, ou primária, de fundamento de matemática básica, ou de compreensão, pode ser resolvida sem a preocupação da "rotulagem" ou assédio por parte dos colegas, e também porque, como a sequência didática está publicada junto com todas as atividades do plano de aula, $o$ estudante pode revisar, reler e se aventurar inúmeras vezes pelo assunto na sua velocidade e capacidade de sua compreensão. Propõe e executa uma sequência didática realizada sobre um procedimento de solução de problemas para orientar a organização do pensamento a respeito de física. Considera a importância da avaliação como instrumento mediador das necessidades na prática docente, por isso apresenta também a análise de uma avaliação do conteúdo de Física, e conseguiu atrair estudantes que usualmente não tinham bom desempenho na disciplina, ofereceu um perfil das dificuldades de aprendizagem de acordo com o assunto abordado, permitiu um acesso direto e individualizado às dúvidas e procedimento de aula. Além disso poderia ser utilizado com um vídeo em Libras on-line do conteúdo, porém na sala não haviam deficientes físicos.
\end{abstract}

Palavras-chave: Metodologia de Ensino, Transposição Didática, E-Learning, Ensino Híbrido e B-learning 
INTRODUÇÃO - este relato é a respeito da constituição do olhar sobre a prática didática durante o período do estágio na disciplina de Física para uma turma $1^{\circ}$ série do colégio público federal de Santa Catarina. Durante a construção da proposta de estratégia da dinâmica observou-se uma motivação especial: uma estudante durante o acompanhamento das aulas pelo professor Reginaldo questionou a respeito da necessidade de se estudar física - [...]porque estudar mecânica clássica (Física)? Este fato instigou um repensar à prática como inserida nas atividades da vida diária do estudante. Afinal, [...]porque estudar mecânica clássica (Física)? - Porque simplesmente é o início do "modelar" sistemas reais, concretos. Bem como inicia a construção de modelos idealizados, analise de variáveis, consideração da importância da simplificação para a construção do modelo teórico. É tendência que em muitas partes da física não existe mais a preocupação com novos problemas em mecânica newtoniana, mas se busca entender novos sistemas com ferramentas matemáticas nas quais as teorias físicas sejam mais sofisticadas. A importância da modelagem na construção do saber sábio, porque na sua conclusão ele atenta a respeito das simplificações realizadas, em que as "características dissipativas" são desprezadas e os resultados efetivos encontrados com o modelo proposto possuem variáveis que são conservadas e fundamentais na descrição do fenômeno estudado (SAMPAIO, FRACALOSSI, \& OLIVEIRA, 2014).

Por que propor uma interferência pedagógica diferenciada? - Porque devemos estar atentos ao nível de abstração com que se trabalha usualmente um conteúdo de física. Atualmente é comum este nível ser desconexo da realidade ou de um evento cotidiano. Um exemplo é o experimento sugerido para lançamento de projéteis em roteiros e livros que servem de guias para o ensino de Mecânica nos laboratórios didáticos de física experimental. (SAZAKI \& JESUS, 2015). Muito embora sirva como ilustração da lei da conservação de energia, falha na questão de ensino-aprendizagem devido, geralmente, ao professor não discutir quais as considerações e desconsiderações do modelo real para o modelo idealizado. Sazaki (2015) atenta que não há uma descrição em tempo real do movimento e por isso não é possível perceber que uma esfera de um experimento de lançamento de projéteis desliza e rola na maior parte de um percurso, só alcança a condição de rolamento puro ao final da plataforma. Esse equívoco no tratamento é o motivo da sistemática diferença entre o balanço de energia previsto e aquele obtido pelas medidas experimentais. A proposta de Sazaki (2015) mostra como resultado que não basta um conteúdo prático se este está distante do fenômeno real, não pelo fenômeno em si, o modelo, mas principalmente porque aquilo que é importante na modelagem, que são as variáveis e vínculos considerados no modelo não são discutidos através da aplicação de um vídeo. Ainda acrescenta uma crítica à experimentação realizada nos laboratórios didáticos com o uso de vídeos, revelando que 
características interessantes do movimento são ofuscadas pela abordagem tradicional. Primeiro mostrando que a hipótese do rolamento puro é falsa, pois tal condição é somente atingida nos instantes finais do movimento, quando a esfera já está na base da calha. Logo, a conservação da energia mecânica não se justifica, a princípio (SAZAKI \& JESUS, 2015). A respeito dos "facilitadores de aprendizagem", Heckler (2007) relata a importância do desenvolvimento e da aplicação de CD-ROM para o ensino médio, abrangendo os conteúdos vistos em uma disciplina. O material proposto por ele deve conter, além de textos didáticos escritos em linguagem HTML, animações e imagens, assim como, por exemplo, simuladores (Java Applets) disponíveis na internet. Os estudantes que participaram do experimento de Heckler (2007) relataram que as aulas elaboradas com a utilização do CD não eram cansativas e como o experimento é compartilhado, existe a troca de conhecimentos, sem a observação de aspectos negativos encontrados pelos estudantes e despertou um maior interesse pelas aulas de física. A partir de sua pesquisa, reitera a importância do uso de novas tecnologias, pois a utilização de novas tecnologias de ensino em aulas de física no ensino médio deve ser feita como uma ferramenta auxiliar, um recurso a mais no processo de ensino/aprendizagem, nunca de forma única, devendo ser aliada aos demais recursos existentes (HECKLER, OLIVEIRA, FILHO, \& SOUZA, 2007).

A CONSTRUÇÃO DO TEMA - Observou-se dificuldades em problemas de matemática básica, operações e até de interpretação dos textos presentes nos exercícios e exemplos propostos. Uma barreira na aprendizagem, bem como de interesse e dedicação da turma pelo estudo de física. O uso de recurso didático com a aplicação da Tecnologia de Informação - TI foi utilizado durante o período de observação da turma com a intensão de minimizar os problemas percebidos. Considerando que todos os estudantes dispunham de telefone celular mesmo que não fossem permitidos durante 0 período de aula. Assim a proposta foi a construção de uma ferramenta de suporte ao aprendizado complementar que se constituiu por um blog estruturado em páginas da seguinte forma: a) Descritiva: com o assunto que seria abordado na "próxima" aula - a intensão é que o estudante conhecesse o tema antes da aula de modo a estar preparado para a aula presencial; b) Conteúdo teórico - com a intensão de demonstração das equações da aula; c) Plano de aula e o tempo de cada recurso didático - intensão de percepção pelo estudante da dinâmica da aula; d) Exemplos de exercícios resolvidos - intensão de suporte ao conteúdo ministrado em sala; e) Lista de exercícios complementares - intensão de facilitar a aprendizagem individual; f) Contato e mensagem por e-mail e um chat para comunicação direta - intensão de permitir aos estudantes um contato direto em tempo real com estagiário, professor e colegas.

O TEMA da interferência em sala de aula é: A Tecnologia da Informação e 
comunicação no ensino de Ciências. O uso da tecnologia da informação ocorreu em três momentos distintos: a) um primeiro momento, mais contínuo e intensivo, com a utilização de um "blog" como meio de comunicação, apresentação de listas e fonte de consulta a respeito da disciplina, dúvidas, curiosidades presentes em revistas e jornais de livre circulação como motivador ao aprendizado de Física e também do acesso à ferramenta; b) um segundo momento de uso de tecnologia para o ensino de Física com o uso de simuladores para a ilustração dos problemas propostos em sala, a apresentação dos fenômenos através de simuladores, como por exemplo phet-colorado; e c) o terceiro momento que envolveu o processo de avaliação on-line por meio da ferramenta AVA-Moodle de modo a permitir que os estudantes estejam totalmente envolvidos com as novas tecnologias presentes no ambiente escolar da atualidade.

A FERRAMENTA - As mídias na educação a distância são capazes de contribuir fortemente para a disseminação do ensino, e, segundo Torres (2014) "[...] está em consonância com o Plano Nacional de Educação", e os jovens devem estar preparados para esta tendência. A opção na prática de estágio com o uso de recursos midiáticos e em rede é considerar o fato de que os estudantes já possuem acesso à rede de computadores, telefones e Tablet. Outro fator a considerar é a influência destes recursos nos processos educacionais. Por exemplo, quando uma informação é disponibilizada na internet e acessada pelo estudante, é uma informação desprovida do contexto. Um conteúdo sem a "imersão no cenário" em que o "modelo didático" foi construído, que pode facilmente satisfazer erroneamente o estudante devido ao "imediatismo" da adolescência, mas que não contribui para o aprendizado de Ciência. Com a intensão de avaliar a implementação de uma metodologia híbrida - Blended Learning (b-learning) que é a combinação do aprendizado nos ambientes virtual e presencial, foi desenvolvida uma ferramenta midiática para acesso dos estudantes ao conteúdo de aula, visto que o uso das tecnologias é importante por romper as distâncias e divulgar as informações com maior rapidez. Permite, ainda uma maior interação entre estudantes e professor, e com outros estudantes, de modo a favorecer a construção de saberes de uma maneira coletiva. $O$ ensino-aprendizagem deve ocorrer por comunicação bidirecional em que o estudante não pode ser colocado como um receptor passivo, mas um ator ativo, crítico e ciente. A relação do estudante com o professor e com o conteúdo que lhe é disponibilizado, deve ocorrer em um ambiente de construção permitindo o diálogo sobre uma base sólida de conhecimento. A prática educativa com a adoção de uma metodologia híbrida oportuniza aos estudantes um olhar de diferentes perspectivas de um mesmo tema, o que promove aplicação e construção do conhecimento a partir de diversas percepções e experiências. Tal prática permite uma aprendizagem mais autônoma (BÉVORT, BELLONI, 2009), porque o estudante pode buscar o conteúdo em qualquer tempo e lugar. O suporte desta ferramenta com o contato docente permite que 
o estudante resolva suas deficiências e dúvidas por chat ou E-mail, e ainda a segurança que o contato entre as pessoas favorece na construção coletiva da aprendizagem. As barreiras a serem transpostas quanto à utilização da tecnologia no ensino presencial é um fator fundamental para o desenvolvimento educacional dos estudantes, porque 0 sucesso depende tanto da implementação na rede de computadores quanto da efetiva utilização pelos estudantes da ferramenta proposta. O B-learning refere-se a um sistema de formação na qual parte dos conteúdos é transmitido em curso à distância, que inclui situações presenciais, misto (blended). O B-learning é estruturado com atividades síncronas ou assíncronas, onde os estudantes trabalham juntos em um horário prédefinido, ou não, cumprindo suas tarefas com horários flexíveis. (TORRES, BORBA, DE SOUZA, \& MARTINS, 2014). O Moodle - significa "Modular Object-Oriented Dynamics Learning Environment", que é um software livre, de apoio à aprendizagem, e executado em um ambiente virtual na rede de computadores, "[...] um trabalho colaborativo baseado nesse software ou nessa plataforma, acessível através da Internet ou de rede local' (DOUGLASMAR, 2017). Embora, o Moodle permita tanto um ensinoaprendizagem totalmente à distância, e-learning, quanto um aprendizado misto, $b$ learning, a proposta da ferramenta para o presente estágio é uma ferramenta tipicamente b-learning, porque seu conteúdo é totalmente focado no plano de aula específico de cada aula, obrigatoriamente é complementar à aula presencial corrente na semana, é público, de fácil acesso, e focado no plano de aula do dia da aula.

REVISÃO TEÓRICA - BORGES (2002) analisa como o laboratório escolar de ciências tem sido usado discutindo o papel das atividades práticas no ensino de ciências. Para ele trata-se de "equívocos" as atividades que conduzem as práticas de laboratório, e acrescenta que existem alternativas mais relevantes e pedagogicamente mais interessantes, como a adoção de uma diversidade de atividades práticas e experimentais sem os tradicionais roteiros. Este autor defende a Transposição Didática TD do conteúdo formal do Saber Sábio até atingir no estudante o Saber Aprendido com o objetivo de deslocar o núcleo das atividades dos estudantes da exclusiva manipulação de equipamentos, preparação de montagens e realização de medidas. Pietrocola (1999) aponta para a epistemologia de Mario Bunge como caminho para orientar a reflexão sobre o papel dos modelos em situações de sala de aula. Assim como na compreensão acerca da construção de modelos na Ciência em que se faz uma transposição dessas ideias para o Ensino de Física (MACHADO, 2008). Nesse contexto a transposição ocorre através de construções Bungeanas, enfatizando o objeto modelo e o modelo teórico, considerando o processo de sua construção e a relação existente entre eles. As Pesquisas em ensino de Ciências enfatizam a importância da modelização como objeto de ensino, porque favorece a aproximação entre os conhecimentos escolares e o cotidiano do estudante. Porém é uma prática comum nas escolas procurar identificar os 
conhecimentos com a realidade a qual expõe o conflito existente entre a percepção imediata que o aluno possui das coisas e os conteúdos ministrados confiantemente pelo professor. (MARTINAND, 1986, 1996; PIETROCOLA 1999; PINHEIRO, 1996). O conhecimento produzido exclusivamente a partir da percepção cotidiana é deficiente e deve ser enriquecido pelo conhecimento teórico. Por outro lado, a explicação teóricocientífica não constitui uma cópia da realidade, mas uma representação simbólica sempre imperfeita, porém aperfeiçoável, da mesma. (CUPANI \& PIETROCOLA, 2002, p. 124). Paradoxalmente a conquista conceitual da realidade começa por idealizações, no momento em que se extraem as características similares dos eventos diferentes, agrupando-os em classes de equivalência. "É o nascimento do objeto-modelo ou modelo conceitual de uma coisa ou de um fato" (BUNGE, 1974, p. 13). Os modelos teóricos podem ser distribuídos de acordo com a profundidade exigida pelos objetivos da pesquisa, constituindo as caixas negras. Estas são consideradas apenas por entradas e saídas de acordo com o objetivo exclusivo de descrição e previsão de conduta, sem se preocupar com o mecanismo interno do objeto ou evento real ou suposto como tal. (BUNGE, 1974). Segundo os estudos de Chevallard (2005), o professor não realiza a transposição didática, ele apenas participa de uma etapa dela, sendo um instrumento de divulgação do saber, ensinando e perpetuando a transmissão dos saberes. (In. NEVES, 2011)

O MÉTODO DAS AULAS - As aulas tiveram um aspecto tradicional, com aulas dialogadas em que a introdução do conteúdo sempre foi fundamentada em uma atividade da vida diária das pessoas, realizando a imersão do conteúdo ministrado na realidade do cotidiano dos estudantes. Os assuntos foram distribuídos de modo a facilitar o reconhecimento individuais, quando relacionado com outro assunto e também para avaliar o reconhecimento a priori por associação de um fenômeno representado através de uma gravura com a lei física correspondente. As questões discutidas em aula foram elaboradas de maneira a permitir uma análise compartimentada das respostas em função do assunto abordado em sala, importante salientar que esse objeto de estudo tem o objetivo de verificar o aprendizado da Física, na Transposição Didática - TD, do saber sábio da academia para o saber ensinar das Universidades e Faculdades, para então se transforma naquele saber que é o saber sábio da escola de nível médio. Esse saber sábio que sofre a TD que virá a ser o saber ensinado na sala de aula, até chegar no saber aprendido pelo estudante. Até então educadores tem discutido em muito a ciência do ensinar, o que discute a seguir é uma sequência didática, uma proposta de estrutura de como o estudante pode resolver um problema, porque talvez a maior dificuldade do estudante seja de como organizar suas ideias, afinal, como se aprende em mecânica, se gasta mais energia para iniciar o movimento do que para mantê-lo. Transformar a solução do problema em si como um desafio, uma barreira a ser 
transposta, e não apenas como aquele "jeito de fazer para acertar na prova", talvez seja a maior dificuldade do professor, então se propõe, e se aplica uma sequência de procedimentos como "um método" de solução de problemas. O impacto significativo dessa proposta é justamente naquele estudante com maior dificuldade em física, e que, provavelmente, com essa "reorganização de seus procedimentos", deve também ter uma melhora nas outras áreas do conhecimento nas quais sejam necessárias análise de cenários reais para uma modelização adequada às leis e teorias das ciências. A ferramenta midiática, diferentemente do Moodle ou outra proposta de gestão acadêmica, tem um aspecto totalmente docente, nela fica exposto o plano de aulas do dia, com a sequência didática, os tempos dedicados e os exemplos resolvidos em sala; o conteúdo teórico do saber sábio com as demonstrações e análises das caixas pretas do dia; importante salientar que isso é colocado ao domínio público "a priori", antecipando a aula presencial de modo a permitir ao estudante uma pré-avaliação do conteúdo, isso impacta na dinâmica da aula. Primeiro porque, por não ser novidade, a atenção do estudante deve estar nas suas dificuldades a respeito daquilo apresentado como objeto da aula, segundo, porque permite a antecipação dos problemas relacionados com a aula, mas que não são os objetos dessa, por exemplo, fundamentos matemáticos. Finalmente, a sequência dessa antecipação permite uma "mudança de postura" frente aos estudos, que tomada como hábito, transforma estudantes em pessoas críticas e atuantes na sociedade buscando a fundamentação antes da retórica.

\section{A SEQUÊNCIA PARA A SOLUÇÃO DE PROBLEMAS - a) Descrever onde a lei,} teoria, ou saber sábio se aplica nas atividades do dia a dia, por exemplo, sobre a associação da energia mecânica potencial elástica e gravitacional na situação do colchão de molas e uma pessoa "senta na cama", a colisão de um veículo com um obstáculo na associação da energia elástica com a cinética na "deformação programada", ou na questão da biologia, por exemplo "as estrias", o "voo da mosca", onde a estrutura "elástica" dela é responsável pela maior parte do batimento das asas para economizar energia. Objetivo: motivacional por demonstrar um valor daquilo que se pretende transmitir, dentre tantos outros valores não menos importantes; b) Ler o problema de modo a realizar a imersão do estudante no cenário proposto, realizar uma inversão, se possível, da descrição colocada no problema, na modelização, para a situação real, por exemplo, utilizando ainda a situação da energia mecânica potencial elástica, largando uma mola, uma "bolinha de massa de modelar" e um copo com um pouco d'água, dessa forma permite ao estudante a percepção dos diferentes fenômenos envolvidos, energia elástica, a deformação do meio elástico, e a terceira lei de newton, presente na queda do copo mas também na reação da mola quando do impacto. Além de toda a ciência física envolvida, a deformação da mola, presente na cama de molas, a deformação além da constante da mola, a estria e a massa de modelar, e a força de 
ação e reação presente na "mola torácica da mosca". Objetivo: Imersão que, embora não transponha a barreira que é resolver o problema, permite agregar esforços para a compreensão da transposição do fato concreto ao modelo ao modelo idealizado, o que terá impacto na construção do saber científico do estudante; c) selecionar os dados: identificar as informações relevantes da situação simplificada exposta no problema. Objetivo: Discutir quais foram as variáveis relevantes, quais outras condições foram desprezadas e porquê disso, permitir que o estudante comece a questionar a modelização em si; d) realizar a análise dimensional: relacionar as unidades oferecidas pelo problema com aquelas dos sistemas métricos tradicionais. Objetivo: Garantir a uniformidade e coerência das ações na solução do problema, fator decisivo em todas as áreas do conhecimento humano; e) observar as leis envolvidas: Relacionar o fenômeno descrito no problema com a ciência em estudo, explicitar as leis. Objetivo: associar o objeto do conteúdo programático com o fenômeno estudado, quais as leis que podem e porque outras não podem ser consideradas com a descrição e a modelização do fenômeno. Afinal o objetivo fundamental é a observação do "caminho" para então atingir ao resultado esperado, e, finalmente, comparar com o evento real, porque a ciência está no percurso e não no resultado; f) Realizar a substituição das variáveis nas equações e teorias envolvidas: Executar o procedimento de associação do modelo idealizado com o resultado esperado do fenômeno real. Objetivo: confirmar o caminho da ciência, do fenômeno real, da idealização, da modelização, e finalmente da comprovação da validade dessa modelização para aquele fenômeno real; g) Avaliação dos resultados: Descrever um resumo do caminho, validando ou não os resultados alcançados com aqueles desejados. Objetivo: Desenvolver no estudante a avaliação de resultados, a análise crítica e autocrítica daquilo que ele se propunha a realizar, o que ele fez, e a relação disso com o que era desejado pelos demais.

OS RESULTADOS - Embora as demonstrações das equações e da "abertura das caixas pretas" por um método formal no quadro e em sala de aula não pareça ser instigante e motivador, se fazem necessárias na medida em que estão presentes nos livros didáticos e, por isso, também estão presentes na interface da tecnologia de informação desenvolvida para o estágio. Portanto, devem ser apresentadas de modo a minimizar a possibilidade da construção de uma barreira de aprendizagem. Apesar de não se exigir um método avaliativo, a existência da demonstração na ferramenta pedagógica, um instrumento da pesquisa, assim como sua demonstração no quadro em sala de aula, são apenas simplificações do fenômeno observado para o modelo idealizado. Evita-se, dessa forma, a construção de barreiras de aprendizagem comuns a situações em que o indivíduo recebe um conteúdo pronto. O rendimento da sala, considerando os valores totais em cada item para nota, foi analisado para que se pudesse verificar os níveis de aprendizagem por assunto, bem como sua contribuição na 
nota total. Avaliando os resultados observou-se que ocorreram $75 \%$ de acertos nas questões de Energia Potencial Gravitacional. Nas questões a respeito da identificação do fenômeno, em que foi levado em conta o reconhecimento e a associação de cada problema em si com a "Física" correspondente, também foi de $75 \%$ de acerto. Ou seja, os estudantes conseguiram relacionar a "situação problema". Nas questões de Energia Potencial Elástica o percentual de acertos foi de $54 \%$ o que está dentro do esperado considerando a nota média da turma foi de 5,89, e, portanto, uma similaridade deveria ser recorrente a todos os itens de avaliação. Nas questões de associação deEnergia Cinética e Energia Potencial Gravitacional, obteve-se 46\% de acertos. As questões envolvendo Energia Potencial Gravitacional foram as que obtiveram melhores escores. Em Matemática Básica, obteve-se 43\% de acertos. Embora durante o período do estágio a matemática pareceu ser uma grande barreira para $57 \%$ da sala. Nas questões de associação de Energia Potencial Elástica e Energia Potencial Gravitacional (26\%), mostra que seria interessante retomar o assunto específico através de exercício. Nas questões de Variação da Energia Total, as relações de conservação de Energia Cinética, o índice de 19,6\% de acertos foi inesperado. Porque, além da equação de conservação de energia parecer mais simples, ela é similar a equação do Movimento Retilíneo Uniformemente Variado - MRUV, e equações de velocidade estão presentes em quase toda a mecânica.

CONCLUSÃO - Destaca-se nos resultados o impacto significativo do uso da ferramenta midiática, que esteve presente durante toda a prática. Não foi realizado "grupo de teste", como também a separação da turma e grupos diferentes para a validação do instrumento, porém não se pode ignorar que o rendimento dos estudantes foi fortemente impactado pelo instrumento midiático. O início do estágio foi com aula tradicional e dialogada, e a ferramenta de apoio à aprendizagem caracterizando um b-learning foi utilizada para a atividade e critérios de avaliação da disciplina neste período. Foi considerada a funcionalidade de diferentes propostas pedagógicas, sejam, a aula expositiva tradicional, o Moodle como ferramenta de gestão e de suporte, e instrumento desenvolvido no estágio com o plano de aulas e exercícios resolvidos, conteúdo programático, e acesso ao E-mail e ao chat para um suporte online em tempo real. Fica claro que as sequências didáticas para as atividades em sala são fundamentais para que se possa ter claras as etapas dos exercícios, e a associação desses com as dificuldades e conteúdo, sem os quais a análise fica complexa e qualitativa, cabendo diferentes formas de interpretação. Portanto os resultados dessa sequência didática, do apoio da ferramenta midiática e da prova foram muito positivos e motivadores de novas análises. No futuro novos estudos a respeito de metodologias alternativas serão realizados, com o intuito de continuamente atualizar os procedimentos para um aprender melhor, continuar-se-á a buscar validar através de procedimentos aplicados a 
associação de diversas e variadas teorias e propostas educacionais com a prática docente no ensino de Ciências.

\section{REFERÊNCIAS}

BÉVORT,E.; BELLONI, M. L.; Mídia - Educação: Conceitos, história e perspectivas; Educ. Soc., Campinas, vol.30, n. 109, p. 1081 - 1102, set./dez. 2009 disponível em: http://www.scielo.br/pdf/es/v30n109/v30n109a08.pdf/. Acesso em maio de 2018

BORGES, T. (dez; de 2002). Novos rumos para o laboratório escolar de ciências. Cad.Bras.Ens.Fís., v. 19, n.3: p.291-313.

BUNGE, M. (1974). Teoria e realidade. São Paulo: Perspectiva.

CHEVALARD, Y. (2005.). La transposición didática:del saber sábio al saber ensiñado.

DOUGLASMAR, M. (2017). Moodle. https://pt.wikipedia.org/wiki/Moodle, 1.

HECKLER, V. S., OLIVEIRA, M. d., FILHO, F., \& SOUZA, K. d. (2007). Uso de simuladores, imagens e animações como ferramentas auxiliares no ensino/aprendizagem de óptica. Rev. Bras. Ensino Fís., ISSN 1806-1117, vol.29, no.2, p.267-273. Internet, P. n. (12/11/2017). https://overbr.com.br/dicas/multimetro-digital-ecalibrador-loopem-1-unico-aparelho. 3.

MACHADO, J., (2008). Modelização no ensino de Física: Contribuições em uma perspectiva Bungeana.

MARTINS, R. A., DA SILVA, G. R., \& CHAGAS, E. (2014). Do saber sábio ao saber ensinar: Uma análise comparativa dos livros do ensino superior e médio. XVII Encontro Nacional de Ensino de Química (XVII ENEQ) (p. 2). Ouro Preto: ED/SBQ.

NEVES, K. O. (2011). Diferentes olhares acerca da Transposição didática, (I. e. Ciências, Ed.), v.16(1).

SAZAKI, D., \& JESUS, V. (Mar 2015). O experimento didático do lançamento horizontal de uma esfera: Um estudo por vídeo análise. Rev. Bras. Ens. Fis., ISSN 1806-1117, vol.37, no.1, p.1507. 